\title{
Comparative Analysis of Performance and Emission Characteristics of Compression Ignition Engine using Biodiesel and Microemulsion Based Bio Fuel Derived from Grape-seeds
}

\author{
Chandanpreet $\operatorname{Singh}^{1}$, Sandeep Singh ${ }^{2}$ and A. K. Sarma ${ }^{3}$ \\ ${ }^{1 \& 2}$ Department of Mechanical Engineering, Punjabi University Patiala, Punjab, India \\ ${ }^{3}$ Scientist-E/Director, Chemical Conversion Department, SSS-NIRE, Kapurthala, Punjab, India \\ E-Mail: chandansinghsaini786@gmail.com
}

\begin{abstract}
Rapid declining of fossil fuel resources has generated awareness towards the development of various alternates to the conventional fuel resources. Grapes being grown worldwide, with India have the potential of making up a good feedstock. Grape-seed oil from grape-seeds was extracted with the aid of Soxhlet apparatus with a maximum yield of $18 \%$. In Biodiesel making, the viscosity of feedstock oil was reduced in a single step transesterification process. Bio Fuel prepared by microemulsification process named as Microemulsion Based Bio Fuel (MBBF). An addition of 1\% 2- Ethylhexyl nitrate was done in MBBF to study its effect in comparison to MBBF itself. In this present work, the Performance and Emission characteristics of a CI engine fuelled with 4 fuels (B20, B100, MBBF and MBBF1\%) were evaluated. The performance parameters studied include Brake Thermal Efficiency, Brake Power and Brake Specific Fuel Consumption, whereas Emissions parameters include Oxides of Nitrogen, Hydrocarbons, Carbon monoxide and Carbon dioxide. The results obtained in the experiment were compared with values of Petrodiesel. Major improvements had been observed in the performance parameters of the engine as well as exhaust emissions. It was concluded that B20 fuel amongst all the Bio Fuels acted as the best alternate fuel.

Keywords: Transesterification, Microemulsion, Compression Ignition, Oxygenated Additive
\end{abstract}

\section{INTRODUCTION}

With the rapid and swift increase in the population of the world, the demand for energy resources has also seen a rise in the last two decades. It's obvious that someday or the other, depletion of these resources would happen. These conclusions led to a search for alternative fuel options to resolve the diminishing energy resources or petroleum reserves. Biodiesel and bio fuels are great alternatives which are environmentally compatible. Thus, energy crisis, global warming and air pollution forced the development of fuels from renewable biological sources. The major exhaust emissions from non-renewable fuels are carbon monoxide (CO), oxides of nitrogen (NOx), oxides of sulphur (SOx), unburnt hydrocarbons (HC) etc. [1]. The rate at which the fossil fuels are consumed is way higher than the rate at which they are being created, therefore they are considered non-renewable [2]. However, Brazil Government has implemented the use of $25 \%$ ethanol as a blending fuel to gasoline in order to fight with their poor economic conditions [3]. The quests for energy alternatives led many methodologies fetching energy from solar and water sources, but are not capable to fulfill the present energy requirements [4].

Biofuels can serve the best alternate to conventional fuel. The alkyl esters produced after transesterification reaction is commonly referred to as biodiesel. The blended form promotes the use of biodiesel in diesel engine without any hardware modification of engine [7, 8]. Biodiesel is miscible in petrodiesel in all different biodiesel to petrodiesel ratios for example B20 i.e. $20 \%$ biodiesel and $80 \%$ petrodiesel [5]. Biodiesel can be made from a variety of common feedstock sources with each country having its own vital feedstock resources. Also the use of biodiesels provides a sure shot economical benefit. Most of them are biodegradable and contribute to sustainability. The properties of biodiesel are close to diesel and it has a considerable environmentally friendly potential [8]. Biodiesel if spilled or released in the environment causes far less damage in comparison to the petrodiesel. It being less combustible makes it safer than petrodiesel. Also, it is far safe to handle, store, and transport [9]. The common problem with biodiesel is that it contains a mixture of saturated and unsaturated fatty acid esters, due to which biodiesel is highly susceptible for auto-oxidation when exposed to ambient air. This oxidation problem results in degradation and formation of undesired by-products, resulting in a poor fuel quality [10].

Micro emulsion based bio fuel is another feasible alternate energy source which can reduce process economics by mixing or blending of vegetable oil or animal fat oil with polar low molecular weight alcohols in order to improve miscibility of polar and nonpolar phases of oil in the presence of surface active agents (surfactants and cosurfactants). The process undergoes sufficient reduction in the interfacial tension between the dispersed or polar phase (e.g. ethanol) and continuous (oil) phases, resulting in making of a bio fuel having most of the fuel properties comparable to diesel and biodiesel. The bio fuel shows similarities with microemulsions, this is the reason behind the terminology of microemulsification.

The benefits of microemulsification in comparison to other methods such as dilution, thermal cracking (pyrolysis) and 
transesterification include lower production costs, short production time, simple and easy implementation and the major reason being is no by-product formation as there is no involvement of chemical reactions [11-15].

The direct use of feedstock vegetable oil or its direct use by blending it with petrodiesel is not possible because of the fact that vegetable oils possess higher viscosity. High viscosity values might result in the ceasing of the fuel line and can reduce the atomization of fuel and increase its penetration level. It would certainly be responsible for deposits in the engine, thickening of the oil and sticking of the piston ring. These high viscosity values are reduced by various methods such as transesterification, dilution, pyrolysis etc. in order to cope up with the engine problems.It is to mark that engine performance and emission characteristics generally depends upon; type of feedstock, biodiesel blend concentrations and engine technology being used [6].

Accordingly, the CI engine performance and emission analysis of Grape-seed oil based biofuel and biodiesel were studied in a single cylinder direct injection CI engine. A comparative study was conducted with B100, B20, MBBF, $\mathrm{MBBF} 1 \%$ and petrodiesel with respect to performance parameters such as brake specific fuel consumption (BSFC), brake thermal efficiency (BTH) and brake power (BP). Whereas the emission values were determined for oxides of nitrogen (NOx), hydrocarbons (HC), carbon dioxide and carbon monoxide (CO).

In the process of MBBF making, n-butanol was used as a co-surfactant in order to mix ethanol and grape-seed oil. Mixing of oil, n-butanol and ethanol were done at various proportions 60:30:10, 60:25:15, 55:25:20 and 50:30:20 out of which 55:25:20 was regarded as the best as it had values near to those of petrodiesel. The tested values were density, kinematic viscosity, calorific value and specific gravity. While making biodiesel, methanol and feedstock oil were mixed in the presence of a catalyst sodium hydroxide $(\mathrm{NaOH})$ in a biodiesel reactor unit. After the completion of the process, glycerol by-product was removed and the biodiesel was subjected to subsequent washing with distilled water. The final biodiesel was attained by removing the excess water from biodiesel by placing it in a hot air oven at $100^{\circ} \mathrm{C}$. India produces around $2967000 \mathrm{Mega}$ Tons over an area of $137000 \mathrm{Ha}$. The production and area figures are published by the Department of Agriculture Cooperation \& Farmers Welfare for the year 2016-2017 [16, 17].

\section{EXPERIMENTAL PROCEDURE}

\section{A. Materials}

Ethanol $(<99 \%)$ and $\mathrm{KOH}(<85 \%)$ were purchased from Merck India Ltd. Methanol $(<99.5 \%)$ and n-butanol $(<98 \%)$ were purchased from Lobe Chemie (India). Phenolpthalein $(<98 \%)$ and $\mathrm{NaOH}(<98 \%)$ were bought from Himedia (India). Whereas, 2-ethylhexyl nitrate $(<99.5 \%)$ was purchased from Sigma Aldrich (India). Grape-seeds were purchased from a local vendor of Pune which were then subjected to extract grape-seed oil with the help of a Soxhlet apparatus. Petrodiesel (LDO, Indian Oil Corporation) was obtained from a local petrol pump in Kapurthala district (Punjab).

\section{B. Preparation of Biodiesel}

Biodiesel sample of Grape-seed oil methyl ester (GOME) is produced using transesterification process in which triglyceride portion of the oil reacts with methanol and $\mathrm{NaOH}$ to form esters and glycerol.

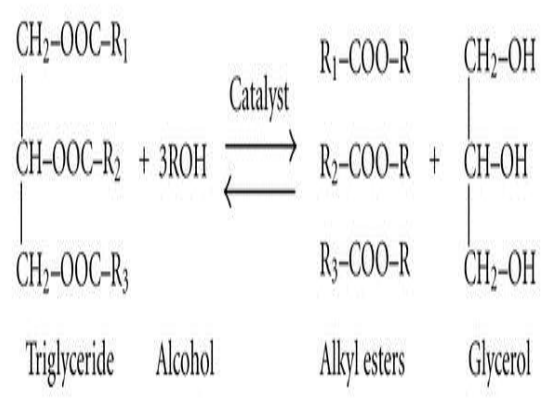

Fig. 1 Transesterification reaction for the production of biodiesel

Its acid value is less $(5.5820 \mathrm{mg}$ of $\mathrm{KOH} / \mathrm{gm}$ of grape-seed oil), so it is to be done in a single step process, otherwise esterification should also have to be done afterward. Esterification process reduces the content of FFA of the oil by converting it into esters.

Grape-seed oil is poured into a flask. Methanol and catalyst $\mathrm{NaOH}$ are mixed and were added to the flask containing grape-seed oil. The $\mathrm{NaOH}$ catalyst being in the form of pellets took several minutes of continuous stirring to mix it with methanol. The mixture is stirred until the $\mathrm{NaOH}$ is fully dissolved in a methanol. The mixture is then heated in the biodiesel reactor unit at a preheated temperature of $65^{\circ} \mathrm{C}$ of the water surrounding the reactor unit. The transesterification reaction is done for 2 hours at a stirring speed of $400 \mathrm{rpm}$. After the completion of the reaction, the mixture is allowed to settle down until the glycerol settles at the bottom. Biodiesel products (biodiesel and glycerol) are transferred into different beakers. The collected biodiesel is given subsequent washing (by distilled water) and drying process. The drying process is carried out in a hot air oven at a temperature slightly above $100^{\circ} \mathrm{C}$ for half hour, so that the slight water can get evaporated and thus leaving behind pure biodiesel. Now we have pure and clean biodiesel free from moisture which is safe to be used.

\section{Preparation of $M B B F$ and $M B B F 1 \%$}

Before going in for preparing MBBF in large quantity, 4 samples (50ml) MBBF's of different ratio's (oil : n-butanol : ethanol) are examined in order to choose the best ratio for preparation of micro emulsion in large quantity. 
Four different ratios (oil: n-butanol : ethanol) examined are:

1. $60: 30: 10$

2. $60: 25: 15$

3. $55: 25: 20$

4. $50: 30: 20$

Grape-seed oil, n-butanol and ethanol are mixed together in the above listed ratios. All these 4 samples are allowed to shake in an electronic shaker at $40^{\circ} \mathrm{C}$ temperature and at $150 \mathrm{rpm}$ for 1 hour. Density, kinematic viscosity and calorific values of all these MBBF samples are determined using density meter, kinematic viscometer and bomb calorimeter respectively. Properties closer to those of petrodiesel were of the $3^{\text {rd }}$ sample $(55: 25: 20)$, so it is selected for preparation. Using similar steps, 2 liter MBBF is prepared $(55: 25: 20)$ and is poured into 2 beakers of 1 liter each. 2-ethylhexyl nitrate is added to one beaker in $1 \%$ volume i.e. $1 \mathrm{ml}$ to 1 liter of MBBF. This process results in two biofuels, namely MBBF and MBBF1\%.

\section{Characterization of feedstock oil, MBBF, MBBF1\%, Biodiesel and Petrodiesel}

GOME is produced using $1 \% \mathrm{NaOH}$ catalyst in methanol in Radley reactor instrument. Some of the common and important fuel properties are tested using ASTM D6751 standards namely; Density, Specific Gravity, Kinematic Viscosity and Calorific Value. Fuel characterization and the comparison are done for $\mathrm{B} 20, \mathrm{~B} 100, \mathrm{MBBF}, \mathrm{MBBF} 1 \%$ and Petrodiesel.

TABLE I COMPARATIVE CHARACTERIZATION OF VARIOUS FUELS FOR DIFFERENT PROPERTIES

\begin{tabular}{|c|c|c|c|c|c|}
\hline Property & $\mathbf{B 2 0}$ & $\mathbf{B 1 0 0}$ & $\mathbf{M B B F}$ & $\begin{array}{c}\text { MBBF } \\
\mathbf{1 \%}\end{array}$ & Diesel \\
\hline $\begin{array}{c}\text { Density at } \\
40^{\circ} \mathrm{C} \\
\left(\mathrm{g} / \mathrm{cm}^{3}\right)\end{array}$ & 0.82768 & 0.86726 & 0.84926 & 0.84987 & 0.81301 \\
\hline $\begin{array}{c}\text { Specific } \\
\text { Gravity }\end{array}$ & 0.83414 & 0.87404 & 0.85589 & 0.85623 & 0.81996 \\
\hline $\begin{array}{c}\text { Kinematic } \\
\text { Viscosity } \\
(\mathrm{cSt})\end{array}$ & 2.9646 & 4.3184 & 6.1763 & 6.1816 & 2.2 \\
\hline $\begin{array}{c}\text { Calorific } \\
\text { Value } \\
(\mathrm{KJ} / \mathrm{Kg})\end{array}$ & 42200 & 41000 & 38000 & 38054 & 43000 \\
\hline
\end{tabular}

\section{E. Experimental Setup (Engine Setup)}

The engine performance and emission characteristics of the fuels (B20, B100, MBBF, MBBF1\% and Petro-diesel or B0) are done on a Kirloskar TV1, single cylinder engine. The engine is in connection with eddy current type dynamometer. The engine setup consists of air box, fuel tank, fuel flow measurements, fuel measuring unit, dynamometer, process indicator and engine indicator. The emission analyzer instrument is used to analyze various engine emissions like carbon monoxide, carbon dioxide, NOx, hydrocarbon, etc.

\section{F. Experimental procedure}

All the fuels B20, B100, MBBF, MBBF1\% and petrodiesel were tested on a single cylinder CI engine so as to attain and investigate certain emission and performance characteristics. The emission values were checked for Carbon Monoxide (CO), Carbon Dioxide $\left(\mathrm{CO}_{2}\right)$, Hydrocarbon (HC), Oxides of Nitrogen (NOx). Whereas the performance characteristics checked were Brake thermal efficiency, Brake specific fuel consumption (BSFC) and Brake power (BP). During the testing of each characteristic, values were noted at $0 \%$ load (no load), $20 \%$ load, $40 \%$ load, $60 \%$ load, $80 \%$ load and 100\% load (full load).

\section{RESULTS AND DISCUSSION}

\section{A. Engine Emissions}

Engine emission studies were examined for B20, B100, MBBF, MBBF1\% and Petrodiesel. The emission studies experimented with the aid of AVL gas analyzer. The emission observations based on gases such as carbon monoxide (CO), hydrocarbon (HC), oxides of nitrogen (NOx) and carbon dioxide $\left(\mathrm{CO}_{2}\right)$ were plotted against load as shown in figures 2, 3, 4 and 5 respectively.

\section{B. Carbon Monoxide (CO)}

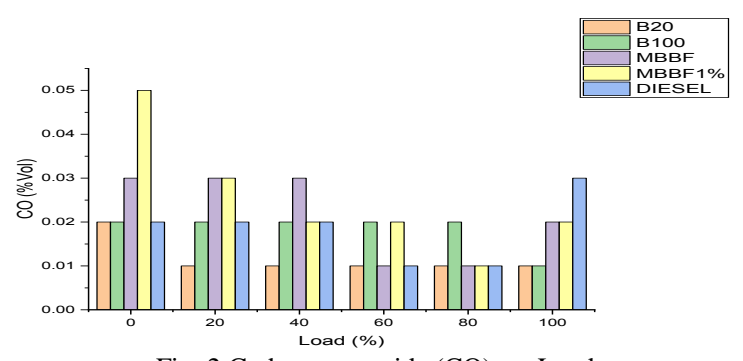

Fig. 2 Carbon monoxide (CO) vs. Load

Carbon Monoxide (CO) emissions were produced during engine emissions either due to incomplete combustion or limited supply of oxygen during combustion as a waste product. At initial loads, the fuel supply is less which results in higher $\mathrm{CO}$ emissions due to the incomplete combustion. As the load increases, the combustion gets proper superior conditions.

It was noticed that $\mathrm{CO}$ emissions by $\mathrm{B} 20$ and $\mathrm{B} 100$ at full load were comparatively less than those of petrodiesel, but were same at no load. This is expected to be observed as the $\mathrm{CO}$ gets converted into $\mathrm{CO}_{2}$ by reacting it with the oxygen present in the biodiesel during combustion. At part and higher loads, values of $\mathrm{CO}$ emissions for MBBF's decreased as these too are oxygenated fuels. The reason for higher $\mathrm{CO}$ emissions for both MBBF'S (MBBF and MBBF1\%) in comparison to petrodiesel at initial loading conditions is that alcohols generate a cooling effect particularly at lower loads which reduces the in-cylinder temperature and contributes to the poor combustion and thus increases $\mathrm{CO}$ emissions. 


\section{Hydrocarbon $(H C)$}

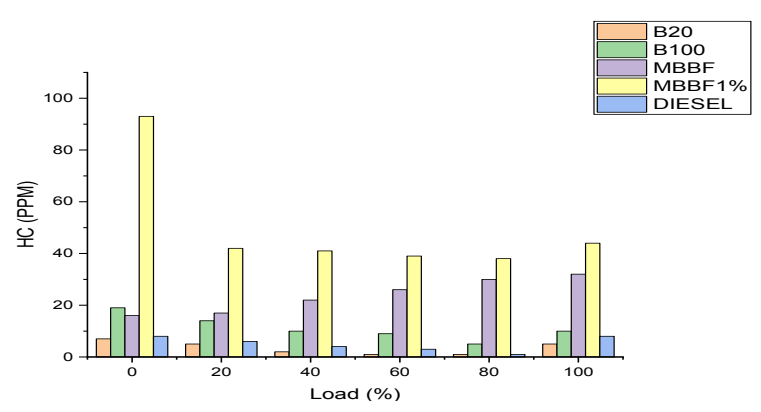

Fig. 3 Hydrocarbons (HC) vs. Load

Un-burnt hydrocarbons are a result produced due to incomplete combustion. $\mathrm{HC}$ emissions were found to be lower for B20 blend in comparison to petrodiesel at almost all variable loads, but were higher for B100 at all variable loads as shown in figure 14. It is also reported in previous studies that $\mathrm{HC}$ emissions using B20 blends come to be lower in value due to the existing oxygen content that helps in complete and cleaner combustion [38, 39]. HC emissions for MBBF's were high as there are heavy triglycerides present in the MBBF's which adds to the inferior combustion conditions. The drastic high values of $\mathrm{HC}$ emission for MBBF1\% are not in accordance with the literature review, however lower percentage values of addition of 2-ethylhexyl nitrate need to be studied.

\section{Oxides of Nitrogen}

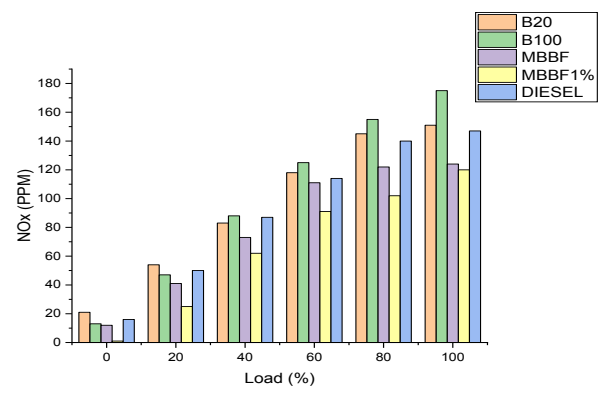

Fig. 4 Oxides of nitrogen (NOx) vs. Load

These emissions contribute to acid rain and smog formation. In general, it is a chemical reaction of oxygen and nitrogen at higher temperatures resulting in the formation of oxides of nitrogen (NOx). NOx formation depends upon combustion temperature, nitrogen residue in the air and the amount of oxygen content in the fuel.

NOx emissions were slightly high for B20 blend but were very much comparable with petrodiesel for all variable loads, but were much higher for B100 in comparison to petrodiesel especially at full loading conditions. The reason for higher values of B100 is due to the oxygen content present in the biodiesel. The MBBF's NOx emissions were quite low in comparison to petrodiesel for all variable loads, but were much less for the MBBF1\% in comparison to MBBF. MBBF's combustion conditions are inferior due to the presence of heavy triglycerides, thus the temperature of the cylinder remains low which reduces the NOx emissions

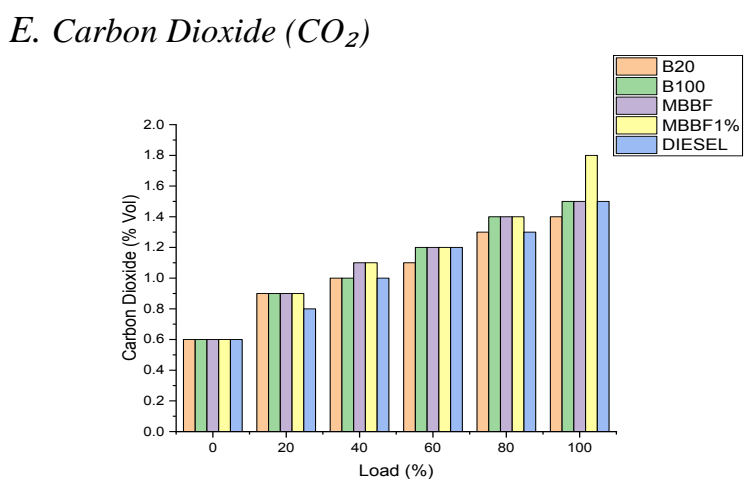

Fig. 5 Carbon dioxide (CO) vs. Load

As known that, carbon dioxide emissions raise the level of global warming and greenhouse gases which leads to climatic changes. As observed for B20, B100, MBBF and MBBF1\% in comparison to petrodiesel, the carbon dioxide emission levels for all variable loads were quite similar and equal except for one or two cases as shown in figure 16.

\section{F. Engine Performance}

Engine performance tests were carried out using B20 blend, B100, MBBF, MBBF1\% and petrodiesel. Several performance parameters studied during the study are:

The results obtained from these parameters were plotted in a bar graph form against variable loads as shown in figure 6 , 7 and 8.

\section{G. Brake Thermal Efficiency}

The brake thermal efficiency increases with rise in load, because inferior combustion conditions are present at lower loads which results in lesser efficiencies. Brake thermal efficiency values of B20 were found to slightly better than those of petrodiesel. Both the MBBF's had similar brake thermal efficiency values for initial loads, but at higher and part loads; the values remained inferior to those of petrodiesel.

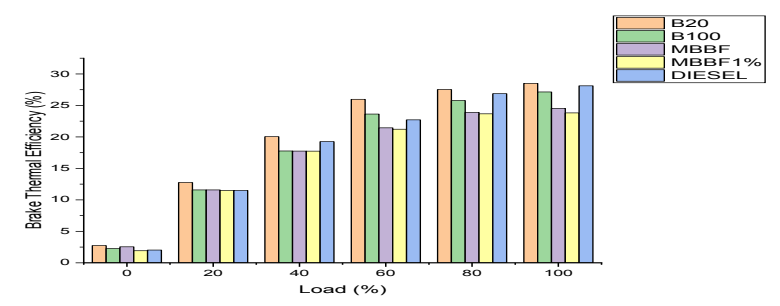

Fig. 6 Brake thermal efficiency vs. Load

\section{H. Brake Specific Fuel Consumption}

Figure 7 shows the variation of brake specific fuel consumption for variable loads. The BSFC values decrease for all fuels when the load is increased gradually. This is due to better combustion conditions at higher loads in 
comparison to the inferior combustion conditions at low load. BSFC depends upon the amount of fuel injected, density, viscosity, calorific value and dissimilar miscellaneous conditions \& parameters. B20 blend showed very low values at initial load. At higher loads, B20 showed slightly better values in comparison to petrodiesel fuel. Very less difference is spotted at all variable loads for B100 fuel. MBBF's values were slightly inferior at almost all loads.

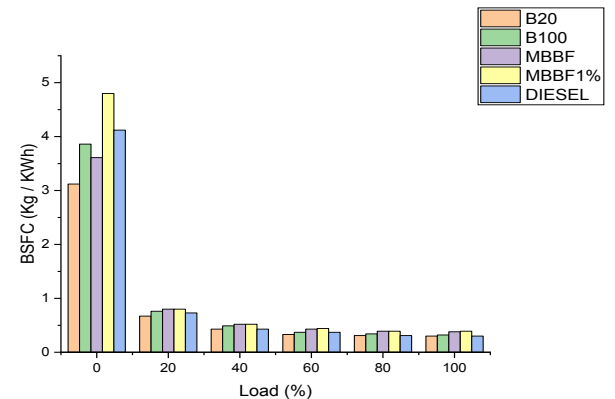

Fig.7 Brake specific fuel consumption (BSFC) vs. Load

\section{Brake Power $(B P)$}

Brake power of the engine rises with the hike in the engine load. This is why an increasing trend has been observed for all fuels. Very negligible differences have been observed for all discrete fuels at variable loads.

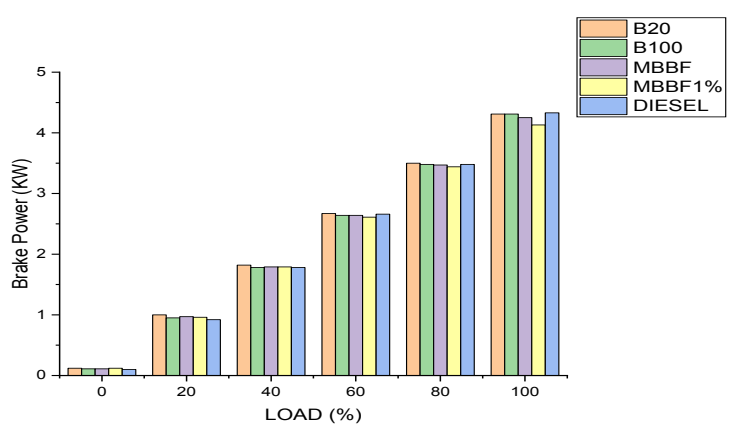

Fig. 8 Brake Power (BP) vs. Load

\section{CONCLUSION}

\section{A. Biodiesel blends vs. Petrodiesel}

1. Carbon monoxide $(\mathrm{CO})$ emissions for both $\mathrm{B} 100$ and B20 decreased by $66.6 \%$ at peak load, whereas CO emissions were similar for both B100 and B20 at minimum load.

2. NOx emissions for B20 were found to be increased by $31.25 \%$ and $2.72 \%$ at minimum and maximum loads respectively. Whereas B100's NOx emissions got reduced by $18.75 \%$ at minimum load, and increased by $19.04 \%$ at maximum load.

3. Carbon dioxide $\left(\mathrm{CO}_{2}\right)$ emissions were similar to those for petrodiesel for B20 and B100 except for a decrease of $6.66 \%$ for B20 fuel at maximum load.

4. $\mathrm{HC}$ emissions by $\mathrm{B} 20$ were found to be $12.5 \%$ less at minimum load and $37.5 \%$ less at peak load. Whereas
HC emissions increased by $137.5 \%$ and $25 \%$ for B100 fuel at minimum and maximum loading conditions.

5. Brake specific fuel consumption decreased by $24.27 \%$ for B20 fuel at minimum load, whereas for B100; it decreased by $6.3 \%$ and increased by $6.66 \%$ at minimum and maximum loading conditions.

6. Brake thermal efficiency consumption values for B20 and B100 increased by $34.97 \%$ and $11.82 \%$ respectively at minimum loading condition, whereas at full load; BTE values for both B20 and B100 decreased b $1.38 \%$ and $3.48 \%$ respectively.

7. Brake power for B20 \& B100 observed an increase of $20 \% \& 10 \%$ for the initial loads. While for full loads, B20 \& B100 values decreased by $0.5 \%$.

\section{B. $M B B F^{\prime} s$ vs. Petrodiesel}

1. The carbon monoxide (CO) emissions for both MBBF's saw a decrease of $33.3 \%$ at peak load. Whereas at minimum loading condition, $\mathrm{CO}$ emissions for $\mathrm{MBBF}$ got an increase of $50 \%$ and $150 \%$ increase for MBBF $1 \%$.

2. NOx emissions for MBBF decreased by $25 \%$ and 15.64 $\%$ at minimum and maximum loading conditions respectively and MBBF1\%'s NOx emissions decreased by $93.75 \%$ and $10.20 \%$ at a minimum and maximum loading conditions respectively.

3. $\mathrm{HC}$ emissions for both $\mathrm{MBBF}$ were higher than petrodiesel by $100 \%$ and $300 \%$ at minimum and maximum loads respectively, but $\mathrm{MBBF} 1 \% \mathrm{HC}$ emissions were drastically high at minimum as well as maximum loads.

4. Carbon dioxide $\left(\mathrm{CO}_{2}\right)$ emissions were exactly the same for $\mathrm{MBBF}$ and $\mathrm{MBBF} 1 \%$ at full and minimum loads except for a $20 \%$ increase in maximum load for MBBF1\%.

5. Brake thermal efficiency for MBBF increased by $25.61 \%$ at minimum load and decreased by $12.73 \%$ at peak load. Whereas BTE values for MBBF1\% decreased by $5.41 \%$ and $15.32 \%$ at minimum load and peak load respectively.

6. Brake specific fuel consumption for MBBF decreased by $12.3 \%$ and increased by $26.6 \%$ at minimum and maximum loads respectively. Whereas the values increased by $16.5 \%$ and $30 \%$ at minimum at maximum loading conditions respectively for $\mathrm{MBBF} 1 \%$.

7. Brake power at zero load got increased by $10 \%$ and $20 \%$ for MBBF \& MBBF1\% respectively. However, it got decreased by $1.8 \%$ \& $4.6 \%$ for both MBBF \& $\mathrm{MBBF} 1 \%$ at full loads respectively.

\section{C. $M B B F$ vs. $M B B F 1 \%$}

The only superior thing about the addition of 2-ethylhexyl nitrate to MBBF is its positive effect on NOx emissions. MBBF1\%'s NOx emissions were found to be $91.66 \%$ less than MBBF values at minimum loading condition. At peak load, MBBF1\%'s NOx emission were $24.1 \%$ less in comparison to MBBF values. 


\section{Biodiesel vs. $M B B F$}

B20 blend was found to be superior in all aspects expect for NOx values, MBBF's showed a drastic decrease in NOx emissions. Other than that, B20 and B100 was found to be better than MBBF's

\section{E. Recommendation}

1. It has been observed that B20 has been regarded as the most superior fuel amongst all. Also in the present study, the use of B20 blend as an alternative fuel to petrodiesel can be done without undergoing any engine modifications and it also possesses an environmental friendly nature.

2. Use of MBBF and MBBF1\% in the engine instead of petrodiesel is also viable as it reduces NOx emissions to a great extent, but the further need for study is there in order to control the very high HC emissions.

3. The addition of $1 \%$ of 2-ethylhexyl nitrate helped to decrease $91.66 \%$ and $24.1 \%$ NOx emissions in comparison to MBBF, but $1 \%$ addition of 2-ethylhexyl nitrate should be avoided.

\section{REFERENCES}

[1] E. F. Aransiola T. V. Ojumu O. O. Oyekola and Ikhuomoregbe, "A Study of Biodiesel Production from Non-edible Seeds, pp. A Comparative Study", Open Conference Proceeding Journal, Vol. 3, pp. 8-12, 2012

[2] A. Demibras, "Biodiesel a Realistic fuel Alternative for Diesel engines", Springer-Verlag London limited, 2008.

[3] N. Kapilan, T.P.A. Babu and R.P. Reddy, "Technical Aspects of Biodiesel and its Oxidation Stability", International Journal of ChemTech Research, Vol. 2, No. 1, pp. 278-282, 2009.
[4] A.P. Singh, A. Dhar and A.K. Agarwal, "Evolving Energy Scenario, pp. Role and Scope for Alternative fuels in Transport Sector", Prospects of Alternative Transportation, pp. 7-19, 2017.

[5] G. Knothe J. Krahl and J.V. Gerpen, "The Biodiesel Handbook", 2010.

[6] A.K. Agarwal J.G. Gupta and A. Dhar, "Potential and Challenges for Large-scale Application of Biodiesel in Automotive Sector", Progress in Energy and Combustion science, Vol. 61, pp. 113-149, 2017.

[7] N. Yilmaz A. Atmanli and M. Trujillo, "Influence of 1-pentanol additive on the Performance of a Diesel Engine Fueled with Waste oil Methyl ester and Diesel fuel”, Fuel, Vol. 207, pp. 461-469, 2017.

[8] A. Demirbas, "Tomorrow's Biofuels, pp. Goals and Hopes", Energy Sources, Part A, Recovery, Utilization, and Environmental Effect, 2017s.

[9] Alternative fuels data center, U.S. department of energy, www.afdc.eergy.gov

[10] G. Joshia J.K. Pandey S. Ranab and D.S. Rawatb, "Challenges and Opportunities for the Application of Biofuel", Renewable and Sustainable Energy Reviews, Vol. 79, pp. 850-866, 2017.

[11] C.E, Goering, "Preparation and properties of diesel fuels from vegetable oils", Fuel, Vol. 66, No. 10, pp. 1372-1378, 1987.

[12] C. Attaphong, "Vegetable oil-based microemulsions using carboxylate based extended surfactants and their potential as an alternative renewable biofuel", Fuel, Vol. 94, pp. 606-613, 2012,

[13] R. Chandra," "Fuel properties of some stable alcohol-diesel microemulsions for their use in compression ignition engines", Energy Fuels, Vol. 21, pp. 3410-3414, 2007.

[14] S.P. Moulik and A.K. Rakshit, "Physicochemistry and Applications of Microemulsions", Journal of Surface Science Technology, pp. 159-186, 2006.

[15] P. Bora, L.J. Konwar, J. Boro, M.M. Phukan, D. Deka and B.K. Konwar, "Hybrid Biofuels from Non-edible oils, pp. A Comparative Standpoint with Corresponding Biodiesel", Applied Energy, Vol. 135, pp. $450-460,2014$.

[16] Department of Agriculture Cooperation \& Farmers Welfare, Ministry of Agriculture, Government of India. www.agricoop.gov.in

[17] National Horticulture Board, Government of India. www.nhb.gov.in. 